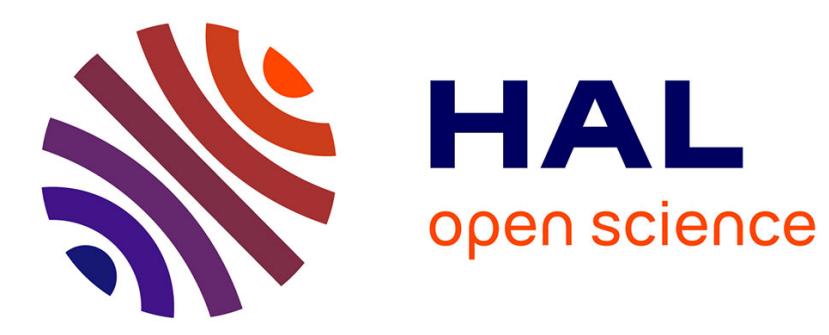

\title{
Wave-particle interaction in a plasmaspheric plume observed by a Cluster satellite
}

\author{
Zhigang Yuan, Ying Xiong, Ye Pang, Meng Zhou, Xiaohua Deng, \\ Jean-Gabriel Trotignon, Elizabeth Lucek, Jingfang Wang
}

\section{- To cite this version:}

Zhigang Yuan, Ying Xiong, Ye Pang, Meng Zhou, Xiaohua Deng, et al.. Wave-particle interaction in a plasmaspheric plume observed by a Cluster satellite. Journal of Geophysical Research Space Physics, 2012, 117, A03205 (9 p.). 10.1029/2011JA017152 . insu-01179996

\section{HAL Id: insu-01179996 \\ https://hal-insu.archives-ouvertes.fr/insu-01179996}

Submitted on 24 Jul 2015

HAL is a multi-disciplinary open access archive for the deposit and dissemination of scientific research documents, whether they are published or not. The documents may come from teaching and research institutions in France or abroad, or from public or private research centers.
L'archive ouverte pluridisciplinaire HAL, est destinée au dépôt et à la diffusion de documents scientifiques de niveau recherche, publiés ou non, émanant des établissements d'enseignement et de recherche français ou étrangers, des laboratoires publics ou privés. 


\title{
Wave-particle interaction in a plasmaspheric plume observed by a Cluster satellite
}

\author{
Zhigang Yuan, ${ }^{1,2}$ Ying Xiong, ${ }^{1}$ Ye Pang, ${ }^{3}$ Meng Zhou, ${ }^{3}$ Xiaohua Deng,,${ }^{1,3}$ \\ Jean Gabriel Trotignon, ${ }^{4}$ Elizabeth Lucek, ${ }^{5}$ and Jingfang Wang ${ }^{1}$ \\ Received 9 September 2011; revised 29 December 2011; accepted 29 December 2011; published 6 March 2012.
}

[1] The wave-particle interaction is a possible candidate for the energy coupling between the ring current and plasmaspheric plumes. In this paper, we present wave and particle observations made by the Cluster $\mathrm{C} 1$ satellite in a plasmaspheric plume in the recovery phase of the geomagnetic storm on 18 July 2005. Cluster C1 simultaneously observed Pc1-2 waves and extremely low frequency (ELF) hiss in the plasmaspheric plume. Through an analysis of power spectral density and polarization of the perturbed magnetic field, we identify that the observed Pc1-2 waves are linearly polarized electromagnetic ion cyclotron (EMIC) waves and show that the ELF hiss propagates in the direction of the ambient magnetic field in whistler mode. In the region where the EMIC waves were observed, the pitch angle distribution of ions becomes more isotropic, likely because of the pitch angle scattering by the EMIC waves. It is shown that the ELF hiss and EMIC waves are spatially separated: The ELF hiss is located in the vicinity of the electron density peak within the plume while the EMIC waves are detected in the outer boundary of the plume because of the different propagation characteristics of the ELF hiss and EMIC waves.

Citation: Yuan, Z., Y. Xiong, Y. Pang, M. Zhou, X. Deng, J. G. Trotignon, E. Lucek, and J. Wang (2012), Wave-particle interaction in a plasmaspheric plume observed by a Cluster satellite, J. Geophys. Res., 117, A03205, doi:10.1029/2011JA017152.

\section{Introduction}

[2] The plasmasphere boundary layer (PBL) is a term used to describe the region of dynamic interaction between the plasma of the inner and outer magnetospheres at the outer extent of the plasmasphere [Carpenter and Lemaire, 2004]. During geomagnetic storms, a plasmaspheric drainage plume transports the cold plasmaspheric plasma from the PBL in the dusk sector to the dayside magnetopause [Elphic et al., 1997; Goldstein et al., 2004; Darrouzet et al., 2009a]. Recent studies of structures and dynamics of the plasmasphere and plasmaspheric plumes using the IMAGE and Cluster measurements have been reviewed by Darrouzet et al. [2009b] and Singh et al. [2011].

[3] Pc1 waves in the frequency range of $0.2-5 \mathrm{~Hz}$ tend to be sporadic in occurrence and are thought to be generated by internal magnetospheric processes. Pc2 waves in the frequency range of $0.1-0.2 \mathrm{~Hz}$ typically arise from the same

\footnotetext{
${ }^{1}$ School of Electronic Information, Wuhan University, Wuhan, China.

${ }^{2}$ Sate Key Laboratory of Space Weather, Chinese Academy of Sciences, Beijing, China.

${ }^{3}$ Institute of Space Science and Technology, Nanchang University, Nanchang, China.

${ }^{4}$ Laboratoire de Physique et Chimie de l'Environnement et de l'Espace, CNRS, University of Orléans, Orléans, France.

${ }^{5}$ Blackett Laboratory, Imperial College London, London, UK.

Copyright 2012 by the American Geophysical Union. 0148-0227/12/2011JA017152
}

physical process as Pc1 waves, which occur more often in the afternoon sector at high latitudes [Fraser, 1968]. Both Pc1 and Pc2 waves are recognized as electromagnetic ion cyclotron (EMIC) waves. Pc1-2 waves in the frequency range of $0.1-5 \mathrm{~Hz}$ in the afternoon sector are most commonly observed below the local helium gyrofrequency [e.g., Ishida et al., 1987; Anderson et al., 1992a]. It is well known that the EMIC waves are generated by a resonant interaction with ring current (RC) ions [e.g., Cornwall 1965; Horne and Thorne, 1993; Fraser and Nguyen, 2001]. The major source of free energy driving this instability is considered to be provided by energetic and anisotropic ring current protons [Anderson et al., 1992b; Erlandson and Ukhorskiy, 2001; Engebretson et al., 2007; Sakaguchi et al., 2008]. The anisotropic proton distributions can become unstable to the amplification of EMIC waves. In the presence of cold dense ions, the instability threshold is so low that EMIC waves can be easily generated [Gary et al., 1995]. Besides strong enhancements of the EMIC wave power at the plasmapause, EMIC waves have been also widely observed outside the plasmapause, giving an increase of the wave occurrence rate with the $L$ shell [Anderson et al., 1992b]. This suggests that the plasmapause and/or the other regions of steep density gradients are not the only preferred sites for the generation of EMIC waves. The other regions, like the plasmaspheric plumes, may also favor the occurrence of the EMIC waves [Fraser and Nguyen, 2001]. Simulations with the HOTRAY code [Horne, 1989] have shown that the high-density 


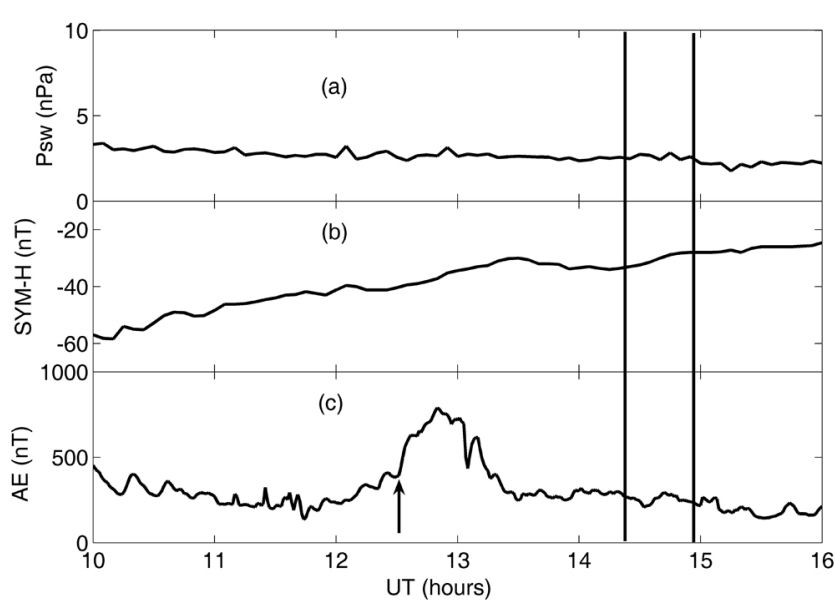

Figure 1. (a) Solar wind dynamic pressure, (b) SYM-H index, (c) $A E$ index between 10:00 and 16:00 UT on 18 July 2005. The arrow in Figure 1c denotes the onset of a substorm at 12:23 UT. The interval of interest is denoted by two vertical solid lines.

drainage plume is one of preferred regions for EMIC wave excitation, and the density structure in the plumes can guide waves [Chen et al., 2009a]. As a result, the negative gradient of radial electron densities leads to a small wave normal angle and an order of enhancement of the wave strength [Chen et al., 2009a]. As a consequence of the RC-EMIC interaction, ring current protons can be scattered into the loss cone and cause subauroral arcs [Fuselier et al., 2004; Jordanova et al., 2007; Yahnin and Yahnina, 2007; Yahnina et al., 2008]. The arcs are located in the midafternoon sector during disturbed periods, during which plasmaspheric plumes can extend sunward from the main plasmasphere [Immel et al., 2002; Spasojević et al., 2004; Fraser et al., 2005, 2006; Yuan et al., 2010].

[4] Plasmaspheric hiss is a broadband, structureless, ELF electromagnetic emission in the frequency range from $\sim 100 \mathrm{~Hz}$ to several kilohertz. This natural whistler mode emission is characteristically confined to higher-density regions associated with the Earth's plasmasphere [Russell et al., 1969; Thorne et al., 1973; Cornilleau-Wehrlin et al., 1993] or detached plasma regions [Chan and Holzer, 1976; Cornilleau-Wehrlin et al., 1978; Parrot and Lefeuvre, 1986]. The hiss within detached plasma has been found to be similar in its banded noiselike structure to the hiss in the main plasmasphere but is characteristically of lower frequency [Chan and Holzer, 1976]. The intensification of ELF hiss has been associated with the injection of plasma sheet electrons into the inner magnetosphere during substorms [Meredith et al., 2004]. One of the consequences of wave-particle interaction by the cyclotron instability between ELF hiss and electrons is the precipitation of energetic electrons into the atmosphere that is due to pitch angle diffusion [Titova et al., 1998; Yuan et al., 2011]. As mentioned above, many observations have demonstrated the wave-particle interaction in the plasmaspheric plume. However, few observations have shown simultaneously ELF hiss and EMIC waves and associated energetic particles scattered into the loss cone in a plasmaspheric plume during a geomagnetic storm, which is very important to reveal wave-particle interaction in the ring currentplasmaspheric plume-ionosphere system.

[5] In this paper, we focus on the wave-particle interaction in the plasmaspheric plume on 18 July 2005. In section 2, we briefly describe the instrumentation on board the Cluster C1 satellite. In section 3, we present observations from Cluster $\mathrm{C} 1$ on 18 July 2005. In section 4, we discuss and summarize the results.

\section{Instrumentation}

[6] The Waves of High Frequency and Sounder for Probing Electron Density by Relaxation (WHISPER) instrument allows one to identify the electron plasma frequency in the frequency range of $2-80 \mathrm{kHz}$ [Décréau et al., 1997, 2001]. These data can be used to analyze the density structure of plasmaspheric plumes when corresponding plasma frequencies lie in this range [Darrouzet et al., 2006]. Electron densities presented in this paper are provided by the Cluster WHISPER instrument at a time resolution of about 2 s. The Hot Ion Analyzer (HIA) sensor of the Cluster Ion Spectrometry (CIS) instrument on board the Cluster spacecraft is an ion spectrometer to measure three-dimensional (3-D) distribution functions of the ions between $5 \mathrm{eV} / \mathrm{q}$ and $32 \mathrm{keV} / \mathrm{q}$ without mass discrimination in one spacecraft spin (4 s) time resolution [Rème et al., 2001]. Thus, measurements of the HIA cover a substantial part of the ring current energy range [Williams, 1987]. The magnetic field is obtained from the Fluxgate Magnetometer (FGM) with a $22 \mathrm{~Hz}$ sampling frequency [Balogh et al., 2001]. The Spectrum Analyzer (SA), which is a part of the Spatiotemporal Analysis of Field Fluctuations (STAFF) experiment [Cornilleau-Wehrlin et al., 1997, 2003], can measure three magnetic field components and two electric field components in the frequency range of $8 \mathrm{~Hz}$ to $4 \mathrm{kHz}$.

\section{Observations}

[7] The event occurred on 18 July 2005. Figure 1 shows, from top to bottom, the solar wind dynamic pressure, the SYM-H index, and $A E$ index. At 07:00 UT, the SYM-H index reached the minimum of $-84 \mathrm{nT}$ (not shown here) and the recovery phase started (Figure 1b). This indicates that the interval shown in Figure 1, i.e., between 10:00 and 16:00 UT, lays in the recovery phase of a geomagnetic storm. As shown in Figure 1a,, between 10:00 and 16:00 UT, the solar wind dynamic pressure is kept in a moderate but stable level. As shown in Figure 1c, the $A E$ index sharply increased at 12:23 UT, implying an onset of a substorm. The auroral observations of the Wideband Imaging Camera (WIC) on the IMAGE satellite [Burch, 2000] also demonstrated the onset of the substorm at 12:23 UT (not shown). The interval delimited by the vertical solid lines is of interest in the present study.

[8] A plume is identified as a significant and localized density enhancement in the region outside the main plasmasphere. To identify a plasma density structure as a probable plume, one can somewhat arbitrarily require that the observed $L$ width of the density enhancement be greater than a given value; we follow the criterion of Darrouzet et al. [2008] to choose the value of 0.2 . To calculate the $L$ shell value of the McIlwain parameter [McIlwain, 1961] at 


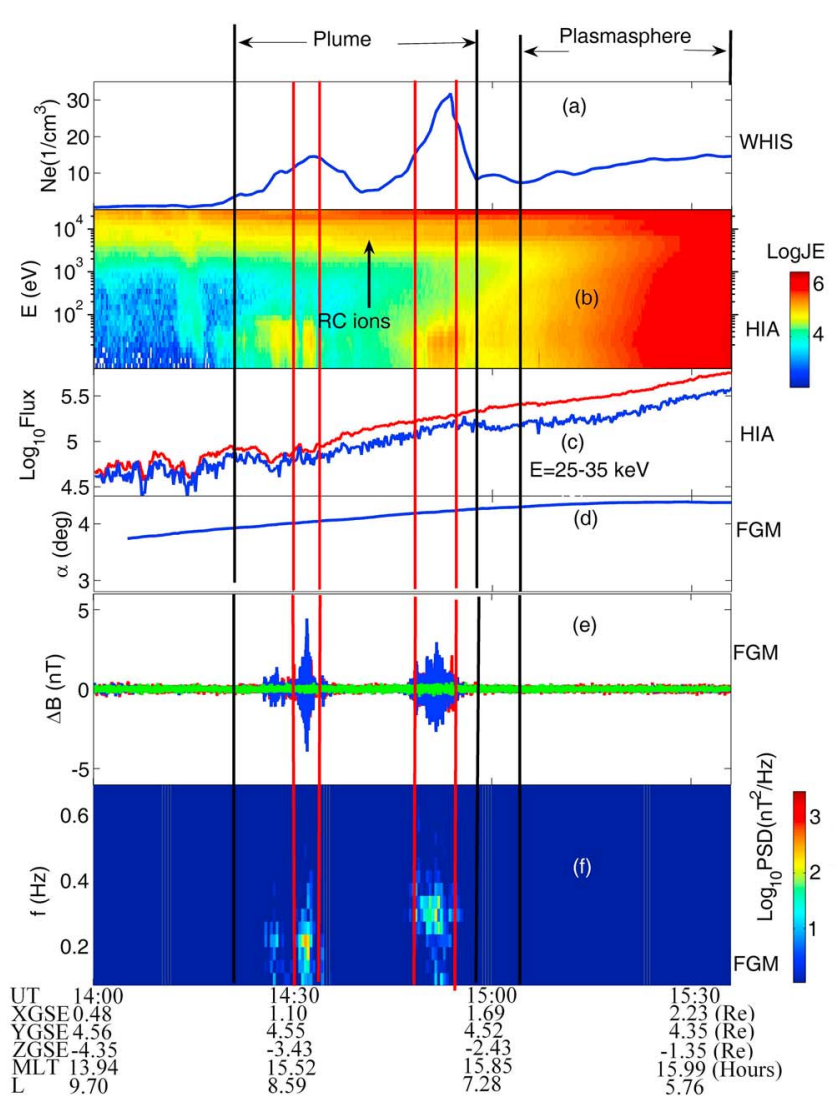

Figure 2. Overview of data from Cluster $\mathrm{C} 1$ between 14:00 and 15:36 UT on 18 July 2005. (a) Electron density derived from the electron plasma frequency detected by the WHISPER instrument. (b) HIA omnidirectional energytime spectrogram in particle flux units (no mass discrimination). (c) Ion flux with energies of $25-35 \mathrm{keV}$ measured by the HIA. Ion fluxes with pitch angles of $80^{\circ}-90^{\circ}$ and $170^{\circ}-180^{\circ}$ are denoted by red and blue lines, respectively. (d) Local loss cone angle along Cluster C1 orbit. (e) Disturbed magnetic field in the field-aligned coordinate system measured by FGM with a time resolution of $0.1 \mathrm{~s}$ derived by using a $25.6 \mathrm{~s}$ running window. The two perpendicular components $\left(\Delta B_{t 1}\right.$ and $\left.\Delta B_{t 2}\right)$ and the field-aligned component $\left(\Delta B_{\mathrm{FA}}\right)$ of perturbed magnetic field in the field-aligned coordinate system are denoted by red, blue, and green solid lines, respectively. (f) Power spectral density (PSD) of the $\Delta B_{t 2}$ component of the disturbed magnetic field. Red vertical solid lines denote two time intervals of enhanced PSDs in the frequency range of Pc1-2 waves. Black vertical solid lines denote boundaries of the plasmaspheric plume and main plasmasphere.

Cluster's location, we use a model that combines the internal magnetic field model IGRF2000 and the external magnetic field model TSK-05, depending on the solar wind pressure, the $D s t$ index, and the interplanetary magnetic field (IMF) $Y$ and $Z$ components [Tsyganenko and Sitnov, 2005]. In addition, we projected Cluster trajectories along the magnetic field onto the equatorial plane in order to derive the $\mathrm{He}^{+}$ gyrofrequency at the equatorial plane $\left(f_{\mathrm{He}+\mathrm{eq}}\right)$.

[9] An overview of Cluster $\mathrm{Cl}$ data including the electron number density, the magnetic field, and power spectral density of one of perpendicular components of the perturbed magnetic field during the time interval from 14:00 to 15:36 UT is shown in Figure 2. Figure 2a shows a plume crossed by Cluster $\mathrm{C} 1$ during the inbound plasmasphere pass on 18 July 2005. Darrouzet et al. [2008] have identified the regions of the two density enhancements shown in Figure 2(a) as substructures of a plasmaspheric plume. When considering the double plume as being a single entity, its boundaries can be defined as the first departure from the background density (observed at 14:17 UT), referred to as the outer boundary, and the final density step toward background density (observed at 14:56 UT), referred to as the inner boundary. Using the TSK-05 model, we locate the outer and inner boundaries of the plume at $L$ values of 9.4 and 7.4 and magnetic local time (MLT) values of 15:14 and $15: 48$, in agreement with the general location of plume structures in the afternoon sector [Darrouzet et al., 2008]. In the plasmaspheric plume, as shown in Figure $2 b$, the ring current is revealed by the presence of strong fluxes of highenergy $(>10 \mathrm{keV})$ trapped ions [Vallat et al., 2004]. Besides the HIA instrument of Cluster $\mathrm{C} 1$, the HIA and CODIF instruments of Cluster $\mathrm{C} 3$ and $\mathrm{C} 4$ also observed energetic ring current ions in the plasmaspheric plume (not shown here). CODIF is equipped with a Retarding Potential Analyzer (RPA), which allows more accurate measurements in the $\sim 0.7-25 \mathrm{eV} / \mathrm{q}$ energy range for the ion species $\left(\mathrm{H}^{+}, \mathrm{He}^{++}, \mathrm{He}^{+}\right.$, and $\left.\mathrm{O}^{+}\right)$, with respect to the spacecraft potential, covering the plasmaspheric energy domain [Rème et al., 2001]. Therefore, the CODIF instrument in the RPA mode is better for detecting plasmaspheric cold and thermal ions, including $\mathrm{H}^{+}, \mathrm{He}^{+}$, and $\mathrm{O}^{+}$[Darrouzet et al., 2006]. Unfortunately the RPA mode of the CODIF instrument was not active during the time interval studied here.

[10] Figure 2c displays ion flux with energies of $25-35 \mathrm{keV}$ measured by the HIA. The ion fluxes with pitch angle of $80^{\circ}-90^{\circ}$ and $170^{\circ}-180^{\circ}$ are denoted by red and blue lines, respectively. The trapped ion flux is usually much greater than the precipitating ion flux. Therefore, to obtain an accurate measurement of the precipitating ion flux, it is important to select data from the HIA only when it is measuring ions inside the loss cone. To do this the loss cone angle at the satellite, corresponding to the edge of the loss cone at Cluster $\mathrm{C} 1$, was determined by assuming conservation of the first adiabatic invariant [Lam et al., 2010]:

$$
\alpha=\sin ^{-1}\left(\sqrt{\frac{B_{\text {sat }}}{B_{120}}}\right),
$$

where $B_{\text {sat }}$ is the ambient magnetic field at the spacecraft and $B_{120}$ is the ambient magnetic field at the "foot of the field line," i.e., the point where the magnetic field threading the satellite intersects $\sim 120 \mathrm{~km}$ in altitude above Earth. The magnetic field $B_{\text {sat }}$ at the satellite can be obtained from measurements of Cluster C1 FGM. The magnetic field $B_{120}$ was calculated using the IGRF2000 model.

[11] Figure 2d shows the loss cone angle at Cluster $\mathrm{C} 1$. Since the local loss cone angle is about $4^{\circ}$, observed ions with pitch angle of $80^{\circ}-90^{\circ}$ should be trapped ions while those with pitch angle of $170^{\circ}-180^{\circ}$ include trapped and precipitating ions. Between 14:29 UT and 15:36 UT the increase of ion flux with pitch angle of $80^{\circ}-90^{\circ}$ and energies of $25-35 \mathrm{keV}$ implies the enhancements of RC density. The 

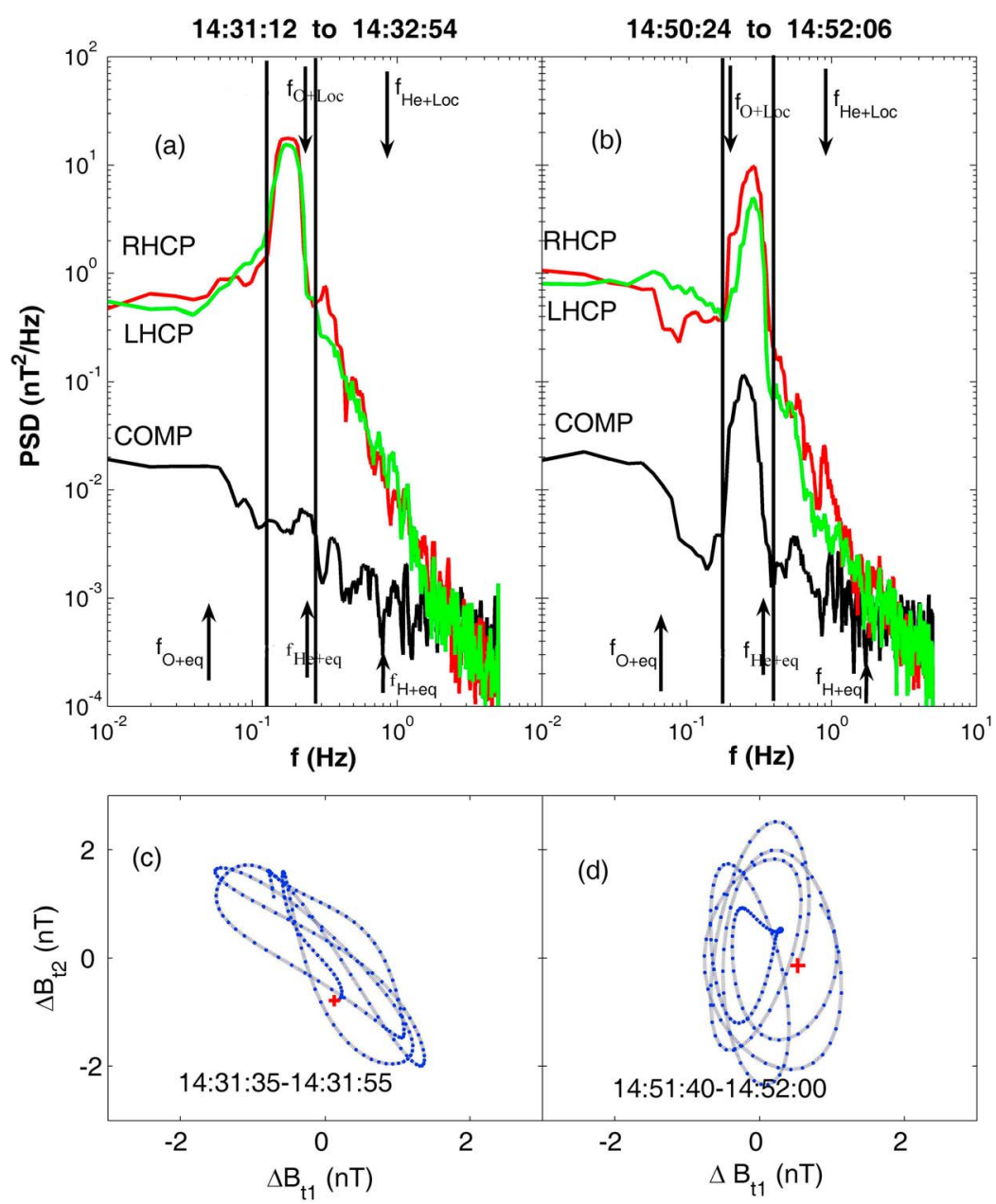

Figure 3. Power spectrum and hodograms of the disturbed magnetic field measured by FGM of Cluster $\mathrm{C} 1$ in the field-aligned coordinate system for time intervals of 14:31:12-14:32:54 UT and 14:50:2414:52:06 UT selected from data of Figure 2. In Figures $3 \mathrm{a}$ and 3b, the power spectrum of left-hand circularized polarization (LHCP), right-hand circularized polarization (RHCP), and compression (COMP) components in the field-aligned coordinate system are denoted by green, red, and black solid lines, respectively. Vertical solid lines denote the frequency band of disturbed magnetic field. In Figures 3c and $3 \mathrm{~d}$, hodograms are referred to two perpendicular components in a plane perpendicular to the ambient magnetic field. Red plus denotes the starting point.

enhancements of RC density partly leads to the increase of ion flux with pitch angle of $170^{\circ}-180^{\circ}$ between 14:29 UT and 15:36 UT. It is important to note that Cluster $\mathrm{C} 1$ left the inner boundary of the plume and detected the decrease of ion flux with pitch angle of $170^{\circ}-180^{\circ}$, which will be discussed in Figure 4.

[12] In order to better extract Pc1-2 waves $(0.1-5 \mathrm{~Hz})$, the high-resolution original data of the magnetic field have been averaged in the interval of $0.1 \mathrm{~s}$ so that the resampling frequency becomes $10 \mathrm{~Hz}$. Thereafter, the average magnetic field is calculated by a $25.6 \mathrm{~s}$ running average with the resampled magnetic field data. Perturbed magnetic fields are calculated by subtracting the average magnetic field from the resampled magnetic field. The average magnetic field is considered the ambient or static magnetic field where Cluster $\mathrm{C} 1$ is located. To better study characteristics of the perturbed magnetic field observed by Cluster $\mathrm{C} 1$, we transform the perturbed magnetic field in GSE coordinates into the field-aligned coordinates. In Figure 2e, two perpendicular components $\left(\Delta B_{t 1}\right.$ and $\left.\Delta B_{t 2}\right)$ and the field-aligned component $\left(\Delta B_{\mathrm{FA}}\right)$ of the perturbed magnetic field are denoted by red, blue, and green solid lines, respectively. In this case, the directions of $\Delta B_{t 1}$ and $\Delta B_{t 2}$ are approximately azimuthal and radial, respectively. Figure $2 \mathrm{e}$ shows that the amplitude of perturbed magnetic field increases in the outer boundary of the plasmaspheric plume, especially during two intervals denoted by red vertical solid lines, i.e., from 14:31 to $14: 33$ UT and $14: 48$ to $14: 54$ UT. During those two intervals, the transverse component $\Delta B_{t 2}$ of perturbed magnetic field is much stronger than the $\Delta B_{\mathrm{FA}}$ component, which means that the direction of the perturbed magnetic field is nearly perpendicular to the ambient magnetic field. As the strongest component of the perturbed magnetic field, $\Delta B_{t 2}$ is used to obtain the power spectral density (PSD) through fast Fourier transforms (FFTs) with $25.6 \mathrm{~s}$ data intervals. Figure $2 \mathrm{f}$ shows the PSD of the $\Delta B_{t 2}$. It is seen 


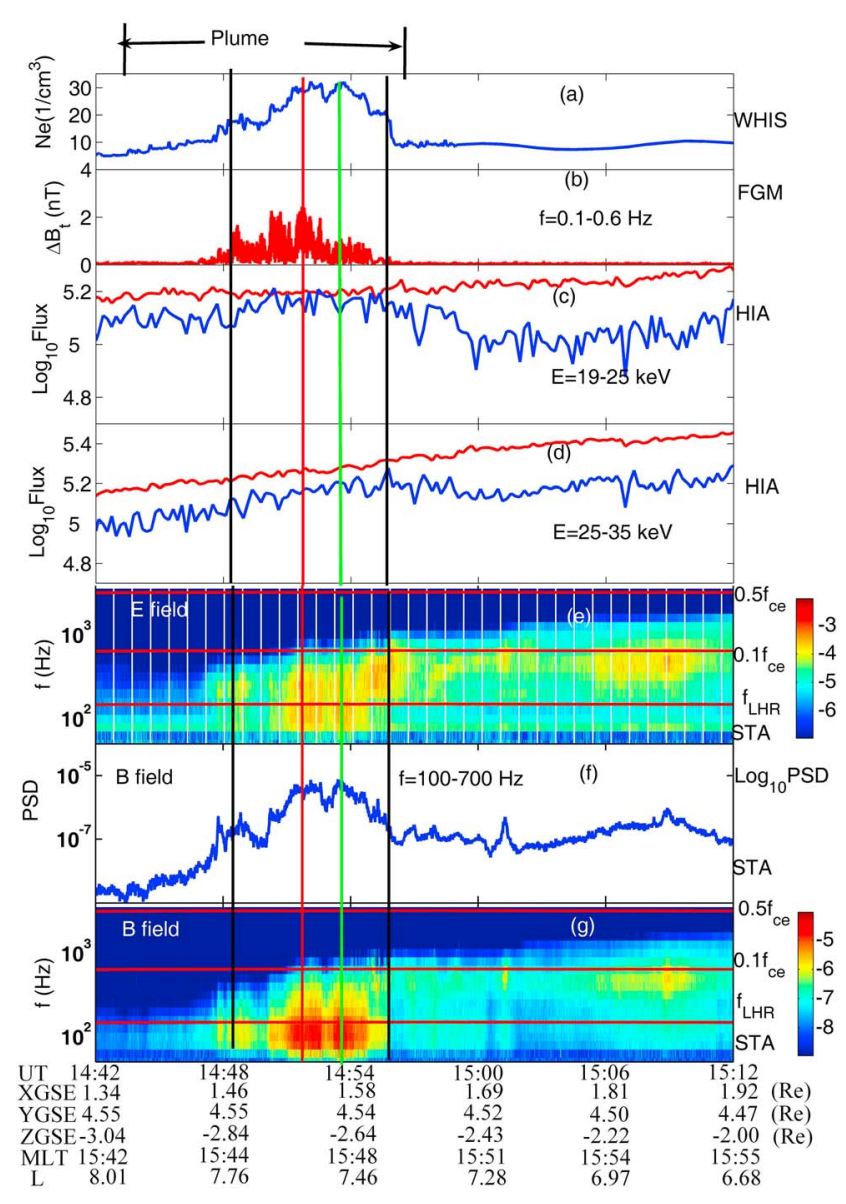

Figure 4. Overview of data from Cluster $\mathrm{C} 1$ between 14:42 and 15:12 UT on 18 July 2005. (a) Electron density derived from the electron plasma frequency detected by the WHISPER instrument. (b) Amplitude of perpendicular components $\left(\Delta B_{t}=\sqrt{\Delta B_{t 1}^{2}+\Delta B_{t 2}^{2}}\right)$ of the disturbed magnetic field measured by FGM through a band-pass filter with a passband of $0.1-0.6 \mathrm{~Hz}$ in the field-aligned coordinates. (c, d) Ion fluxes with energies of $19-25$ and 25$35 \mathrm{keV}$ measured by HIA, respectively. Ion fluxes with pitch angles of $80^{\circ}-90^{\circ}$ and $170^{\circ}-180^{\circ}$ are denoted by red and blue lines, respectively. (e) Electric power spectral density measured by the STAFF instrument. (f, g) Averaged magnetic power spectral densities in the frequency range of $100-700 \mathrm{~Hz}$ and magnetic power spectral densities measured by the STAFF instrument. (e, g) Average values of two electric and three magnetic components, respectively. The two top red solid lines in Figures $4 \mathrm{e}$ and $4 \mathrm{~g}$ denote the $0.5 f_{\text {ce }}$ and $0.1 f_{\text {ce }}$, respectively, the bottom red solid line corresponds to the local lower hybrid resonance frequency $\left(f_{\text {LHR }}\right)$. The red and green vertical solid lines denote the peak amplitudes for Pc1-2 and ELF waves observed by Cluster C1 in the plasmaspheric plume, respectively. Two black vertical solid lines denote the interval of wave-particle interactions in the plasmaspheric plume.

from Figure $2 \mathrm{f}$ that during two intervals denoted by red vertical solid lines the pulsation frequencies lie in the range of $0.1-0.4 \mathrm{~Hz}$, i.e., in the Pc1-2 band.
[13] In order to study polarization characteristics of Pc1-2 waves observed by Cluster $\mathrm{C} 1$, we recombine the two transverse components $\left(\Delta B_{t 1}\right.$ and $\left.\Delta B_{t 2}\right)$ into left- and righthand polarized components $\left(\Delta B_{1}=\Delta B_{t 1}-i \Delta B_{t 2}\right.$ and $\Delta B_{r}=$ $\left.\Delta B_{t 1}+i \Delta B_{t 2}\right)$ [Volwerk et al., 2008]. Figure 3 shows power spectrums of three components $\left(\Delta B_{1}, \Delta B_{r}\right.$, and $\left.\Delta B_{\mathrm{FA}}\right)$ of the perturbed magnetic field in the field-aligned coordinates during two time intervals denoted by red vertical solid lines in Figure 2: 14:31:12-14:32:54 UT and 14:50:2414:52:06 UT. In Figures 3a and 3b, the power spectrum of left-hand circularized polarization (LHCP) $\Delta B_{1}$, right-hand circularized polarization (RHCP) $\Delta B_{r}$, and compression (COMP) component $\Delta B_{\mathrm{FA}}$ in the field-aligned coordinate system are denoted by green, red, and black solid lines, respectively. The local $\mathrm{O}^{+}$and $\mathrm{He}^{+}$ion gyrofrequencies $\left(f_{\mathrm{O}+\mathrm{Loc}}, f_{\mathrm{He}+\mathrm{Loc}}\right)$ are derived from the ambient magnetic field observed by Cluster $\mathrm{C} 1$. On the other hand, the equatorial $\mathrm{H}^{+}$, $\mathrm{He}^{+}$, and $\mathrm{O}^{+}$ion gyrofrequencies $\left(f_{\mathrm{H}_{\mathrm{eq}}}, f_{\mathrm{He}+\mathrm{eq}}, f_{\mathrm{O}+\mathrm{eq}}\right)$ on the field line threading the Cluster $\mathrm{C} 1$ satellite are calculated using the TSK-05 model. As shown in Figure 3a, the frequency band of Pc1-2 waves denoted by two vertical solid lines during the interval of 14:31:12-14:32:54 UT lies in the frequency range of $0.13-0.3 \mathrm{~Hz}$, below $f_{\mathrm{O}+\mathrm{Loc}}$. The band of Pc1-2 waves is between $f_{\mathrm{O}+\mathrm{eq}}$ and $f_{\mathrm{He}+\mathrm{eq}}$, in agreement with the theory of EMIC waves generated in the equatorial plane [Young et al., 1981]. The frequency band near $f_{\mathrm{He}+\mathrm{eq}}$ means that cold $\mathrm{He}^{+}$ions in the plasmaspheric plume have a strong influence on the generation of EMIC waves in the equatorial plane. In the frequency range denoted by two vertical solid lines, the COMP component is much weaker than the LHCP and RHCP components. On the other hand, the LHCP and RHCP components have similar spectral densities, which means that the wave packets are almost linearly polarized in a plane perpendicular to the ambient magnetic field during the interval. In order to better show polarization of those Pc1-2 waves, we use a band-pass filter with a passband of $0.05-0.6 \mathrm{~Hz}$ to process the disturbed magnetic field. The results are shown in Figure $3 \mathrm{c}$ as hodograms for the two perpendicular components of the perturbed magnetic field, displaying almost linear polarization of those Pc1-2 waves. For the second time interval i.e., 14:50:24-14:52:06 UT, the frequency band of Pc1-2 waves denoted by two vertical solid lines in Figure $3 b$ lies in the frequency range of $0.20-0.4 \mathrm{~Hz}$, near $f_{\mathrm{He}+\mathrm{eq}}$ but above $f_{\mathrm{O}}$ +Loc. Power spectral densities of LHCP and RHCP components in Figure 3(b), as well as hodograms in Figure 3(d), demonstrate nearly linear polarization of Pc1-2 waves during the interval. Those Pc1-2 waves with frequencies near $f_{\mathrm{He}+\mathrm{eq}}$ can be identified as EMIC waves generated by anisotropic ring current ions in the equatorial plane [Young et al., 1981; Anderson et al., 1992a].

[14] We focus on the second substructure of the plume observed by Cluster C1 from 14:43 to 14:56 UT. Figure 4 shows the electron number density, the disturbed magnetic field, the ion flux, the disturbed electric field, and power spectral density observed by Cluster C1. In Figure $4 \mathrm{~b}$, the amplitude of perpendicular components $\left(\Delta B_{t}=\right.$ $\left.\sqrt{\Delta B_{t 1}^{2}+\Delta B_{t 2}^{2}}\right)$ of the disturbed magnetic field, processed using a band-pass filter with a passband of $0.1-0.6 \mathrm{~Hz}$, is used to denote the intensification of Pc1-2 waves, which are 


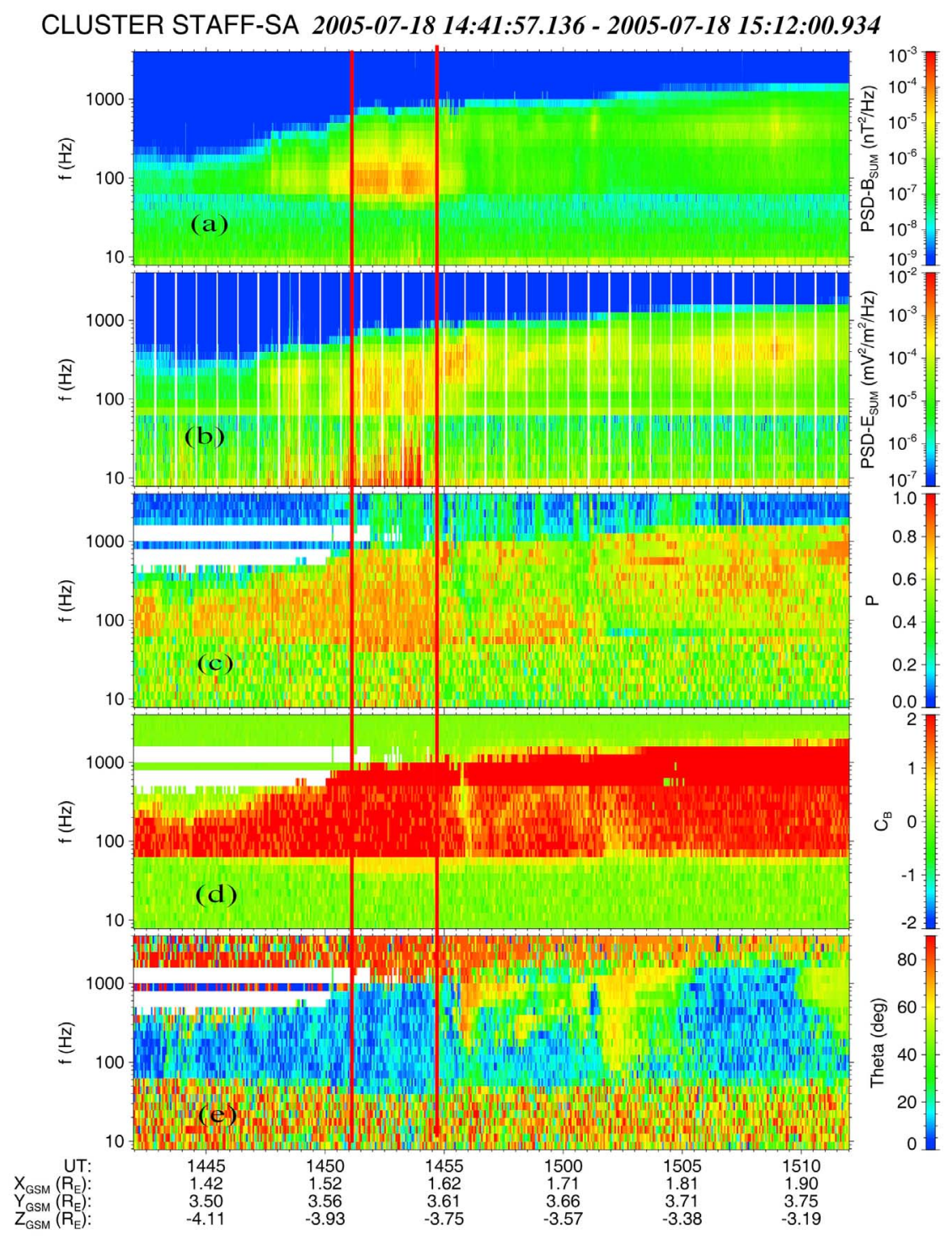

Figure 5. Wave parameters of hiss in the plasmaspheric plume between 14:42 and 15:12 UT on 18 July 2005. (a) Average value of two electric power spectral densities determined by the STAFF instrument. (b) Average value of three magnetic power spectral densities determined by the STAFF instrument. (c) Degree of polarization. (d) Indicator of the sense of polarization. (e) Polar angle of wave normal direction relative to the ambient magnetic field. Two red vertical solid lines denote the interval of hiss enhancement.

mainly enhanced in the outer boundary of the second substructure of the plasmaspheric plume.

[15] Figures $4 \mathrm{c}$ and $4 \mathrm{~d}$ shows the ion flux with energies of $19-25$ and $25-35 \mathrm{keV}$, respectively. Ion fluxes with pitch angles of $80^{\circ}-90^{\circ}$ and $170^{\circ}-180^{\circ}$ are denoted by red and blue lines, respectively. It is seen that in the region of the enhancement of Pc1-2, the ion fluxes with pitch angles $170^{\circ}-180^{\circ}$ increased more sharply than those with pitch angles of $80^{\circ}-90^{\circ}$, implying that the ion pitch angle distribution became more isotropic. When Cluster $\mathrm{C} 1$ left the regions of Pc1-2 waves at about 14:56 UT, the ion fluxes with pitch angles of $170^{\circ}-180^{\circ}$ started to decrease while the ion fluxes with pitch angles of $80^{\circ}-90^{\circ}$ still increased. Since the Pc1-2 waves in the present case are considered as an EMIC wave propagating off the equatorial plane to the
Cluster's location, the more isotropic ion pitch angle distribution is a result of ring current ion scattered by EMIC waves in the plasmaspheric plume.

[16] Figures $4 \mathrm{e}$ and $4 \mathrm{~g}$ shows the electric and magnetic power spectral densities measured by the STAFF instrument. These are the average values of two electric and three magnetic components, respectively. The thin vertical white lines in the electric spectrograms are due to changes in the Wave Experiment Consortium (WEC) experiment mode that temporarily inhibit the observation of natural waves during WHISPER sounding [Décréau et al., 1997]. The two top red solid lines in Figures $4 \mathrm{e}$ and $4 \mathrm{~g}$ show values of $0.5 f_{\text {ce }}$ and $0.1 f_{\text {ce }}$ (where $\mathrm{f}_{\text {ce }}$ is the electron gyrofrequency determined from the measured ambient magnetic field). The bottom red solid line denotes the local lower hybrid resonance 
frequency $\left(f_{\text {LHR }}\right)$. Not only the electric spectrograms but also the magnetic spectrograms show ELF emissions in the frequency range from 70 to $700 \mathrm{~Hz}$ in the plasmaspheric plume. Such ELF emissions can be identified as plasmaspheric hiss [Summers et al., 2008]. Using the method of calculating the spectral intensity of hiss in the frequency range $104<f<$ $1040 \mathrm{~Hz}$ described by Meredith et al. [2004], we define the average magnetic field wave intensities over the frequency range $100<f<700 \mathrm{~Hz}$ as the wave spectral intensity. Figure $4 \mathrm{f}$ shows averaged magnetic power spectral densities. Such ELF hiss observed by the STAFF instrument was located in the vicinity of the electron density peak of the plasmaspheric plume and enhanced with increased plasma density. As shown in Figure 4, two red and green vertical solid lines denote the peak amplitudes for Pc1-2 and ELF waves, respectively. During the interval of wave-particle interactions denoted by two black vertical solid lines in Figure 4, in comparison with the peak amplitude of ELF hiss in Figure 4f, the peak amplitude of Pc-2 waves in Figure $4 \mathrm{~b}$ was located at a larger $L$ value in the plasmaspheric plume.

[17] Using the Propagation Analysis of STAFF-SA Data with Coherency tests (PRASSADCO) method [Santolik, 2001; Santolik et al., 2001], we derive wave parameters of the ELF hiss. Figure 5 shows the magnetic and electric power spectral densities determined by the STAFF instrument, as well as wave propagation parameters. Figures $5 \mathrm{a}-5 \mathrm{~b}$ shows ELF emissions in the frequency range from 70 to $700 \mathrm{~Hz}$. Figure $5 \mathrm{c}$ shows the degree of polarization obtained from the eigenvalues of the magnetic spectral matrix. A value close to 1.0 corresponds to the presence of a single plane wave [Parrot et al., 2003]. The value for the ELF hiss is between 0.8 and 0.9 . This high value gives us confidence in the results of the wave polarization and propagation parameters given in Figures 5d-5e. Figure 5d indicates, with levels of confidence, the sense of polarization with respect to the local magnetic field. Values below -1 mean a left-hand polarized field, values above +1 correspond to the right-hand polarization, and values between -1 and +1 indicate a low confidence level. In Figures $5 \mathrm{c}-5 \mathrm{e}$, the white areas correspond to absolute values of sense of polarization below 0.2. The ELF hiss is right-hand polarized. Figure 5e shows the polar angles of the wave normal direction relative to the Earth's magnetic field (as given by the Cluster Science Data System (CSDS) Prime Parameters (PP) of FGM). It is seen that ELF hiss with right-hand polarization propagates in the direction of the Earth's magnetic field. Figure $4 \mathrm{a}$ shows the electron number density more than $10 \mathrm{~cm}^{-3}$ in the plume, corresponding to a local plasma frequency higher than $29 \mathrm{kHz}$. Therefore, as shown in Figures $4 \mathrm{a}$ and $4 \mathrm{~g}$, frequencies of the ELF hiss lie below both the electron gyrofrequency and the plasma frequency. As a result, the ELF emissions in the interval denoted by red vertical solid lines in Figure 5 are ELF hisses in whistler mode in the plasmaspheric plume.

\section{Discussion and Summary}

[18] Plasmaspheric plumes have been routinely observed in global plasmaspheric images made by the extreme ultraviolet (EUV) imager on board the IMAGE spacecraft [Sandel et al., 2003; Goldstein et al., 2004; Spasojević et al., 2004]. However, the EUV imager of the IMAGE spacecraft did not provide images during the interval of the interest in the present study. By plotting electron densities along the trajectories of four Cluster spacecrafts projected along the magnetic field lines onto the GSM frame, Darrouzet et al. [2008] have shown a plasmaspheric plume from premidnight through postnoon local times. Between 14:48 and 14:55 UT, as shown in Figure 4, Cluster $\mathrm{C} 1$ observed the Pc1-2 waves and ELF hiss at about 15:40-15:50 MLT with a plasmaspheric plume in the afternoon sector.

[19] After the onset of a substorm, energetic ions and electrons are injected from local midnight and drift toward dayside. Since electric drifts for the plasma particles with energies $E>25 \mathrm{keV}$ are negligible in comparison with gradient and curvature drifts, energetic ions drift westward while energetic electrons drift eastward around the Earth. As a result, ion and electron fluxes in the ring current with an anisotropic pitch angle distribution are enhanced in the afternoon sector [Sibeck et al., 1987].

[20] In the presence of cold dense ions, the anisotropic RC proton distributions can become unstable to the amplification of EMIC waves. Therefore, it is expected that EMIC waves occur in the region of overlap between plasmaspheric plumes and ring currents [Fraser and Nguyen, 2001]. In Figures $4 \mathrm{a}-4 \mathrm{~d}$, we have observed those EMIC waves in the plasmaspheric plume. With the occurrence of EMIC waves, as shown in Figures $4 b-4 d$, the pitch angle distribution becomes more isotropic, which is attributed to RC ions scattered into the loss cone by EMIC waves. Erlandson and Ukhorskiy [2001] have shown that EMIC waves scatter ring current protons into the loss cone in the equatorial magnetosphere with observations of the DE1 satellite. Since the MLat of Cluster $\mathrm{C} 1$ is about $-30^{\circ}$ during the interval, the observations of Cluster $\mathrm{C} 1$ are off the equatorial plane. Therefore, Cluster $\mathrm{C} 1$ observed a result of pitch angle scatter caused by EMIC waves through the propagation path of EMIC waves from its source in the equatorial plane to the location of Cluster $\mathrm{C} 1$.

[21] As a result of whistler mode waves amplified by a gyroresonant interaction with energetic electrons with anisotropic distributions, the ELF hiss can be observed in the afternoon sector and associated with plasma density enhancements in the outer magnetosphere [Chan and Holzer, 1976]. As shown in Figures $4 \mathrm{a}$ and $4 \mathrm{e}-4 \mathrm{~g}$, the intensity of ELF hiss increases with the plasma density enhancement in the plume, which is consistent with previous observations [Chan and Holzer, 1976]. The enhancement of ELF hiss is in the vicinity of electron density peak while Pc1-2 waves mainly occur in the outer boundary of the second substructure of the plasmaspheric plume. With coordinated observations of GOES-9 and DMSP F-13 satellites and the ground-based geomagnetic observatory at Chokurdakh (CHD), Morley et al. [2009] have suggested that the favored propagation path for EMIC waves in the plume is along the outer edge of the plume. The CRRES satellite also observed EMIC waves at the outer edges of drainage plume [Fraser et al., 2008]. The favored propagation path of EMIC waves is responsible for the fact that the anisotropic RC ion distributions start before the occurrence of EMIC waves observed by Cluster $\mathrm{C} 1$ in the plasmaspheric plume in Figures $4 \mathrm{a}-4 \mathrm{~d}$. For the formation of ELF hiss, a threedimensional ray tracing of a whistler mode chorus in a realistic magnetosphere demonstrated that ELF waves can 
propagate into the plasmaspheric plume and tend to remain confined inside the plume [Chen et al., 2009b]. As a result, the ELF hiss is in the vicinity of electron density peak and enhances with the increase of plasma density in the plume [Titova et al., 1998]. Therefore, different propagation characteristics of ELF hiss and EMIC waves are responsible for the above partly spatial separation of the occurrence region of the observed ELF hiss and EMIC waves in the plasmaspheric plume. The ELF hiss can scatter energetic electrons into the loss cone, while energetic ions can be scattered into the loss cone by EMIC waves. Since thermal $(<25 \mathrm{keV})$ electron distribution data are provided by the PEACE instrument [Johnstone et al., 1997], we have checked the data of electrons measured by the PEACE instrument of Cluster $\mathrm{C} 1$. However, since the angle resolution $\left(15^{\circ}\right)$ of PEACE was much larger than the local loss cone angle $\left(4^{\circ}\right)$ at Cluster $\mathrm{C} 1$, no obvious increases of isotropy of energetic electron pitch angle distribution were detected with enhancements of ELF hiss.

[22] In summary, during the geomagnetic storm on 18 July 2005, with observations of Cluster $\mathrm{C} 1$, we have presented wave and particle observations in a plasmaspheric plume. The major conclusions are as follows:

1. Cluster C1 simultaneously observed Pc1-2 waves and ELF hiss in the plasmaspheric plume. Through an analysis of power spectral density and polarization of the perturbed magnetic field, we identify that the observed Pc1-2 waves are linearly polarized EMIC waves and show that the ELF hiss propagates in the direction of the ambient magnetic field in whistler mode. ELF hiss and EMIC waves are spatially separated: The ELF hiss is located in the vicinity of the electron density peak within the plume while the EMIC waves are detected in the outer boundary of the plume because of the different propagation characteristics of the ELF hiss and EMIC waves.

2. The pitch angle distribution of ions became more isotropic, which is considered a result of pitch angle scattering caused by EMIC waves on the wave propagation path from its source to the location of Cluster C1.

[23] Since ELF hiss and EMIC waves are spatially separated, it is expected that the precipitation of energetic protons is latitudinally separated from that of energetic electrons because of wave-particle interaction. In order to better demonstrate the relation between the wave activities (ELF hiss, EMIC waves) and energetic ion and electron precipitation in plasmaspheric plumes, conjugate observations of the Cluster satellite in the plasmasphere and low-altitude satellites (NOAA DMSP) at ionospheric altitudes are necessary, which will be discussed in a future study.

[24] Acknowledgments. We thank the Cluster teams (FGM, WHISPER, CIS, STAFF) and Cluster Active Archive (CAA) at http://caa.estec.esa.int/ caa for the high-quality data and successful operation. Solar wind data were obtained from the GSFC/SPDF OMNIWeb interface at http://omniweb. gsfc.nasa.gov. The $A E$ and SYM-H index data are provided by the World Data Center for Geomagnetism at Kyoto University. Z.G. Yuan thanks P. M. E. Décréau for her helpful discussion. This research is supported by the National Natural Science Foundation of China (40974088, 41174140), the Fundamental Research Funds for the Central Universities (4081003), open Research Fund Program of the Sate Key Laboratory of Space Weather, Chinese Academy of Sciences, and the Scientific Research Foundation for Returned Overseas Chinese Scholars, State Education Ministry.

[25] Robert Lysak thanks the reviewers for their assistance in evaluating this paper.

\section{References}

Anderson, B. J., R. E. Erlandson, and L. J. Zanetti (1992a), A statistical study of Pc1-2 magnetic pulsations in the equatorial magnetosphere: 2. Wave properties, J. Geophys. Res., 97(A3), 3089-3101, doi:10.1029/ 91JA02697.

Anderson, B. J., R. E. Erlandson, and L. J. Zanetti (1992b), A statistical study of Pc1-2 magnetic pulsations in the equatorial magnetosphere: 1. Equatorial occurrence distributions, J. Geophys. Res., 97(A3), 3075-3088, doi:10.1029/91JA02706.

Balogh, A., et al. (2001), The Cluster magnetic field investigation: Overview of in-flight performance and initial results, Ann. Geophys., 19, 1207-1217, doi:10.5194/angeo-19-1207-2001.

Burch, J. L. (2000), Image mission overview, Space Sci. Rev., 91, 1-14, doi:10.1023/A:1005245323115.

Carpenter, D. L., and J. Lemaire (2004), The plasmasphere boundary layer, Ann. Geophys., 22, 4291-4298, doi:10.5194/angeo-22-4291-2004.

Chan, K. W., and R. E. Holzer (1976), ELF hiss associated with plasma density enhancements in the outer magnetosphere, J. Geophys. Res., 81(13), 2267-2274, doi:10.1029/JA081i013p02267.

Chen, L., R. M. Thorne, and R. B. Horne (2009a), Simulation of EMIC wave excitation in a model magnetosphere including structured high-density plumes, J. Geophys. Res., 114, A07221, doi:10.1029/ 2009JA014204.

Chen, L., J. Bortnik, R. M. Thorne, R. B. Horne, and V. K. Jordanova (2009b), Three-dimensional ray tracing of VLF waves in a magnetospheric environment containing a plasmaspheric plume, Geophys. Res. Lett., 36, L22101, doi:10.1029/2009GL040451.

Cornilleau-Wehrlin, N., R. Gendrin, F. Lefeuvre, M. Parrot, R. Grard, D. Jones, A. Bahnsen, E. Ungstrup, and W. Gibbons (1978), VLF electromagnetic waves observed onboard GEOS-1, Space Sci. Rev., 22, 371-382, doi:10.1007/BF00210874.

Cornilleau-Wehrlin, N., J. Solomon, A. Korth, and G. Kremser (1993), Generation mechanism of plasmaspheric ELF/VLF hiss: A statistical study from GEOS 1 data, J. Geophys. Res., 98(A12), 21,471-21,479, doi:10.1029/93JA01919.

Cornilleau-Wehrlin, N., et al. (1997), The Cluster Spatio-Temporal Analysis of Field Fluctuations (STAFF) experiment, Space Sci. Rev., 79, 107-136, doi:10.1023/A:1004979209565.

Cornilleau-Wehrlin, N., et al. (2003), First results obtained by the Cluster STAFF experiment, Ann. Geophys., 21, 437-456, doi:10.5194/angeo21-437-2003

Cornwall, J. (1965), Cyclotron instabilities and electromagnetic emission in the ultra low frequency and very low frequency ranges, J. Geophys. Res., 70(1), 61-69, doi:10.1029/JZ070i001p00061.

Darrouzet, F., et al. (2006), Analysis of plasmaspheric plumes: CLUSTER and IMAGE observations, Ann. Geophys., 24, 1737-1758, doi:10.5194/ angeo-24-1737-2006.

Darrouzet, F., J. De Keyser, P. M. E. Décréau, F. El Lemdani-Mazouz, and $X$. Vallières (2008), Statistical analysis of plasmaspheric plumes with Cluster/WHISPER observations, Ann. Geophys., 26, 2403-2417, doi:10.5194/angeo-26-2403-2008.

Darrouzet, F., et al. (2009a), Plasmaspheric density structures and dynamics: Properties observed by the CLUSTER and IMAGE missions, Space Sci. Rev., 145(1-2), 55-106, doi:10.1007/s11214-008-9438-9.

Darrouzet, F., J. De Keyser, and V. Pierrard (Eds.) (2009b), The Earth's Plasmasphere: A CLUSTER and IMAGE Perspective, 296 pp., Springer, Berlin.

Décréau, P. M. E., P. Fergeau, V. Krasnosels'kikh, M. Lévêque, P. Martin, O. Randriamboarison, F. X. Sené, J. G. Trotignon, P. Canu, and P. B. Mögensen (1997), Whisper, a resonance sounder and wave analyser: Performances and perspectives for the Cluster mission, Space Sci. Rev., 79, 157-193, doi:10.1023/A:1004931326404.

Décréau, P. M. E., et al. (2001), Early results from the Whisper instrument on Cluster: An overview, Ann. Geophys., 19, 1241-1258, doi:10.5194/ angeo-19-1241-2001.

Elphic, R. C., M. F. Thomsen, and J. E. Borovsky (1997), The fate of the outer plasmasphere, Geophys. Res. Lett., 24(4), 365-368, doi:10.1029/ 97GL00141.

Engebretson, M. J., et al. (2007), Cluster observation of Pc 1-2 waves and associated ion distributions during the October and November 2003 magnetic storms, Planet. Space Sci., 55, 829-848, doi:10.1016/j. pss.2006.03.015.

Erlandson, R. E., and A. Ukhorskiy (2001), Observations of electromagnetic ion cyclotron waves during geomagnetic storms: Wave occurrence and pitch angle scattering, J. Geophys. Res., 106(A3), 3883-3895, doi:10.1029/2000JA000083.

Fraser, B. J. (1968), Temporal variations in Pcl geomagnetic micropulsations, Planet. Space Sci., 16, 111-124, doi:10.1016/0032-0633(68) 90048-2. 
Fraser, B. J., and T. S. Nguyen (2001), Is the plasmaspause a preferred source region of electromagnetic ion cyclotron waves in the magnetosphere?, J. Atmos. Sol. Terr. Phys., 63, 1225-1247, doi:10.1016/S13646826(00)00225-X.

Fraser, B. J., H. J. Singer, M. L. Adrian, and D. L. Gallagher (2005), The relationship between plasma density structure and EMIC waves at geosynchronous orbit, in Inner Magnetosphere Interactions: New Perspectives From Imaging, Geophys. Monogr. Ser., vol. 159, edited by J. L. Burch et al., pp. 55-70, AGU, Washington, D. C., doi:10.1029/159GM04.

Fraser, B. J., T. M. Loto'aniu, and H. J. Singer (2006), Electromagnetic ion cyclotron waves in the magnetosphere, in Magnetospheric ULF Waves. Synthesis and New Directions, Geophys. Monogr. Ser., vol. 169, edited by K. Takahashi et al., pp. 195-212, AGU, Washington, D. C. doi:10.1029/169GM13.

Fraser, B. J., R. S. Grew, H. J. Singer, J. C. Green, M. F. Thomsen, and R. R. Anderson (2008), Electromagnetic ion cyclotron waves, plasma drainage plumes and geomagnetic storms, Eos Trans. AGU, 89(53), Fall Meet. Suppl., Abstract SM41C-02.

Fuselier, S. A., S. P. Gray, M. F. Thomsen, E. S. Claflin, B. Hubert, B. R. Sandel, and T. Immel (2004), Generation of transient dayside subauroral proton precipitation, J. Geophys. Res., 109, A12227, doi:10.1029/2004JA010393.

Gary, S. P., M. F. Thomsen, L. Yin, and D. Winske (1995), Electromagnetic proton cyclotron instability: Interactions with magnetospheric protons, J. Geophys. Res., 100(A11), 21,961-21,972, doi:10.1029/95JA01403.

Goldstein, J., B. R. Sandel, M. F. Thomsen, M. Spasojević, and P. H. Reiff (2004), Simultaneous remote sensing and in situ observations of plasmaspheric drainage plumes, J. Geophys. Res., 109, A03202, doi:10.1029/ 2003JA010281.

Horne, R. B. (1989), Path-integrated growth of electrostatic waves: The generation of terrestrial myriametric radiation, J. Geophys. Res., 94(A7), 8895-8909, doi:10.1029/JA094iA07p08895.

Horne, R. B., and R. M. Thorne (1993), On the preferred source location for the convective amplification of ion cyclotron waves, J. Geophys. Res., 98(A6), 9233-9247, doi:10.1029/92JA02972.

Immel, T. J., S. B. Mende, H. U. Frey, L. M. Peticolas, C. W. Carlson, J.-C. Gérard, B. Hubert, S. A. Fuselier, and J. L. Burch (2002), Precipitation of auroral protons in detached arc, Geophys. Res. Lett., 29(11), 1519, doi:10.1029/2001GL013847.

Ishida, J., S. Kokubun, and R. L. McPherron (1987), Substorm effects on spectral structures of Pc 1 waves at synchronous orbit, J. Geophys. Res., 92(A1), 143-158, doi:10.1029/JA092iA01p00143.

Johnstone, A. D., et al. (1997), PEACE: A plasma electron and current experiment, Space Sci. Rev., 79, 351-398, doi:10.1023/A:1004938001388.

Jordanova, V. K., M. Spasojević, and M. F. Thomsen (2007), Modeling the electromagnetic ion cyclotron wave-induced information of detached subauroral proton arcs, J. Geophys. Res., 112, A08209, doi:10.1029/ 2006JA012215.

Lam, M. M., R. B. Horne, N. P. Meredith, S. A. Glauert, T. Moffat-Griffin, and J. C. Green (2010), Origin of energetic electron precipitation $>30 \mathrm{keV}$ into the atmosphere, J. Geophys. Res., 115, A00F08, doi:10.1029/ 2009JA014619.

McIlwain, C. E. (1961), Coordinates for mapping the distribution of magnetically trapped particles, J. Geophys. Res., 66(11), 3681-3691, doi: 10.1029/JZ066i011p03681.

Meredith, N. P., R. B. Horne, R. M. Thorne, D. Summers, and R. R. Anderson (2004), Substorm dependence of plasmaspheric hiss, J. Geophys. Res., 109, A06209, doi:10.1029/2004JA010387.

Morley, S. K., S. T. Ables, M. D. Sciffer, and B. J. Fraser (2009), Multipoint observations of Pc1-2 waves in the afternoon sector, J. Geophys. Res., 114, A09205, doi:10.1029/2009JA014162.

Parrot, M., and F. Lefeuvre (1986), Statistical study of the propagation characteristics of ELF hiss observed on GEOS 1, inside and outside the plasmasphere, Ann. Geophys., 4, 363-384.

Parrot, M., O. Santolík, N. Cornilleau-Wehrlin, M. Maksimovic, and C. C. Harvey (2003), Source location of chorus emissions observed by CLUSTER, Ann. Geophys., 21, 473-480, doi:10.5194/angeo-21-473-2003.

Rème, H., et al. (2001), First multispacecraft ion measurements in and near the Earth's magnetosphere with the identical CLUSTER ion spectrometry (CIS) experiment, Ann. Geophys., 19, 1303-1354, doi:10.5194/angeo-191303-2001.

Russell, C. T., R. E. Holzer, and E. J. Smith (1969), OGO 3 observations of ELF noise in the magnetosphere, 1. Spatial extent and frequency of occurrence, J. Geophys. Res., 74(3), 755-777, doi:10.1029/JA074i003p00755. Sakaguchi, K., K. Shiokawa, Y. Miyoshi, Y. Otsuka, T. Ogawa, K. Asamura, and M. Connors (2008), Simultaneous appearance of isolated auroral arcs and Pc 1 geomagnetic pulsations at subauroral latitudes, J. Geophys. Res., 113, A05201, doi:10.1029/2007JA012888.
Sandel, B. R., J. Goldstein, D. L. Gallagher, and M. Spasojević (2003), Extreme ultraviolet imager observations of the structure and dynamics of the plasmasphere, Space Sci. Rev., 109, 25-46, doi:10.1023/B: SPAC.0000007511.47727.5b

Santolík, O. (2001), Propagation Analysis of Staff-SA Data with Coherency Tests, LPCE/NTS/073, C, Lab. Phys. Chimie Environ./CNRS, Orléans, France.

Santolík, O., F. Lefeuvre, M. Parrot, and J. L. Rauch (2001), Complete wave-vector directions of electromagnetic emissions: Application to INTERBALL-2 measurements in the nightside auroral zone, J. Geophys. Res., 106(A7), 13,191-13,201, doi:10.1029/2000JA000275.

Sibeck, D. G., R. W. McEntire, A. T. Y. Liu, R. E. Lopez, and S. M. Krimigis (1987), Magnetic field drift shell splitting: Cause of unusual dayside particle pitch angle distributions during storms and substorms, J. Geophys. Res., 92(A12), 13,485-13,497, doi:10.1029/ JA092iA12p13485.

Singh, A. K., R. P. Singh, and D. Siingh (2011), State studies of Earth's plasmasphere: A review, Planet. Space Sci., 59(9), 810-834, doi:10.1016/j.pss.2011.03.013.

Spasojević, M., H. U. Frey, M. F. Thomsen, S. A. Fuselier, S. P. Gary, B. R. Sandel, and U. S. Inan (2004), The link between a detached subauroral proton arc and a plasmaspheric plume, Geophys. Res. Lett., 31, L04803, doi:10.1029/2003GL018389.

Summers, D., B. Ni, N. P. Meredith, R. B. Horne, R. M. Thorne M. B. Moldwin, and R. R. Anderson (2008), Electron scattering by whistler-mode ELF hiss in plasmaspheric plumes, J. Geophys. Res., 113, A04219, doi:10.1029/2007JA012678.

Thorne, R. M., E. J. Smith, R. K. Burton, and R. E. Holzer (1973), Plasmaspheric hiss, J. Geophys. Res., 78(10), 1581-1596, doi:10.1029/ JA078i010p01581.

Titova, E. E., et al. (1998), Strong localized variations of the low-altitude energetic electron fluxes in the evening sector near the plasmapause, Ann. Geophys., 16, 25-33, doi:10.1007/s00585-997-0025-2.

Tsyganenko, N. A., and M. I. Sitnov (2005), Modeling the dynamics of the inner magnetosphere during strong geomagnetic storms, J. Geophys. Res., 110, A03208, doi:10.1029/2004JA010798.

Vallat, C., et al. (2004), First comparisons of local ion measurements in the inner magnetosphere with ENA magnetospheric image inversions: Cluster-CIS and IMAGE-HENA observations, J. Geophys. Res., 109, A04213, doi:10.1029/2003JA010224.

Volwerk, M., R. Nakamura, W. Baumjohann, T. Uozumi, K. Yumoto, and A. Balogh (2008), Tailward propagation of Pi2 waves in the Earth's magnetotail lobe, Ann. Geophys., 26, 4023-4030, doi:10.5194/angeo-264023-2008.

Williams, D. J. (1987), Ring current and radiations belts, Rev. Geophys., 25(3), 570-578, doi:10.1029/RG025i003p00570.

Yahnin, A. G., and T. A. Yahnina (2007), Energetic proton precipitation related to ion-cyclotron waves, J. Atmos. Sol. Terr. Phys., 69 , 1690-1706, doi:10.1016/j.jastp.2007.02.010.

Yahnina, T. A., H. U. Frey, T. Bosinger, and A. G. Yahnin (2008), Evidence for subauroral proton flashes on the dayside as the result of the ion cyclotron interaction, J. Geophys. Res., 113, A07209, doi:10.1029/ 2008JA013099.

Young, D. T., S. Perraut, A. Roux, C. de Villedary, R. Gendrin, A. Korth, G. Kremser, and D. Jones (1981), Wave-particle interactions near observed on GEOS 1 and 2: 1. Propagation of ion cyclotron waves in He+ rich plasma, J. Geophys. Res., 86(A8), 6755-6772, doi:10.1029/ JA086iA08p06755.

Yuan, Z., X. Deng, X. Lin, Y. Pang, M. Zhou, P. M. E. Décréau, J. G. Trotignon, E. Lucek, H. U. Frey, and J. Wang (2010), Link between EMIC waves in a plasmaspheric plume and a detached subauroral proton arc with observations of Cluster and IMAGE satellites, Geophys. Res. Lett., 37, L07108, doi:10.1029/2010GL042711.

Yuan, Z., L. Zhao, Y. Xiong, X. Deng, and J. Wang (2011), Energetic particle precipitation and the influence on the sub-ionosphere in the SED plume during a super geomagnetic storm, J. Geophys. Res., 116, A09317, doi:10.1029/2011JA016821.

X. Deng, Institute of Space Science and Technology, Nanchang University, Jiangxi, Nanchang 330031, China.

E. Lucek, Blackett Laboratory, Imperial College London, Prince Consort Road, London SW7 2AZ, UK.

Y. Pang and M. Zhou, Institute of Space Science and Technology, Nanchang University, Nanchang 330031, China.

J. G. Trotignon, Laboratoire de Physique et Chimie de l'Environnement et de l'Espace, CNRS, University of Orléans, 3A av. de la Recherche Scientifique, F-45071 Orléans CEDEX 02, France.

J. Wang, Y. Xiong, and Z. Yuan, School of Electronic Information, Wuhan University, Wuhan 430072, China. (y_zgang@vip.163.com) 